\title{
Community building and knowledge sharing by individuals with disabilities using social media
}

\author{
Kayla S. Sweet ${ }^{1}$ (D) । Jennifer K. LeBlanc ${ }^{2}$ । Laura M. Stough ${ }^{1}$ (i) । Noelle W. Sweany ${ }^{1}$ (i)
}

\author{
${ }^{1}$ Department of Educational Psychology, \\ Texas A\&M University, College Station, Texas \\ ${ }^{2}$ Middle School Science, Dostyk American \\ International School, Atyrau, Kazakhstan \\ Correspondence \\ Kayla Sweet, Department of Educational \\ Psychology, 4225 Texas A\&M University, \\ College Station, TX 77840. \\ Email: mrs.sweet07@yahoo.com
}

\begin{abstract}
The use of social media to share information, enhance learning, and connect with an online community has grown rapidly over the past 10 years. As social media becomes a more common tool in both formal and informal education, it is imperative to understand how it is used by individuals with disabilities. Through a systematic study of the literature, 215 articles on social media used by individuals with disabilities were selected and 29 selected for in-depth thematic analysis. Six major themes were identified: community, cyberbullying, self-esteem, self-determination, access to technology, and accessibility. To confirm these six categories, we expanded our search, yielding an additional 30 articles, for a total 59 articles reviewed in-depth. Interactions between individuals with disabilities within online communities often had the goal of acquiring knowledge or learning new information. A communities of practice theoretical framework is used to discuss interactions among the elements of social media design, learning, and the building of community by individuals with disabilities.
\end{abstract}

\section{KEYWORDS}

disabilities, social media, social networking

\section{1 | INTRODUCTION}

Social media involves various digital communication forms such as text, images, and videos through which users interact with the intent to share information and that often results in the creation of online communities. Social media typically involves social networking sites such as Facebook, Linkedln, and Pinterest; microblogging tools such as Twitter and Tumblr; or media sharing tools such as Instagram and YouTube. Each tool allows users to post information, interact with others, and build online communities according to mutual interests. As a result, the contemporary conceptualization of "community" has evolved from one that necessitated physical proximity to one that includes exchanges among individuals who may never meet face-toface. Similarly, the conceptualization of "learning" has shifted to include informal learning supported by technology and knowledge management structures. Siemens (2005) has proposed the theory of connectivism to describe such learning as the "process that occurs within nebulous environments of shifting core elements - not entirely under the control of the individual. Learning (defined as actionable knowledge) can reside outside of ourselves (within an organization or a database), is focused on connecting specialized information sets, and the connections that enable us to learn more are more :mortant than our current state of knowing" (para. 23

The term communities of practice (CoP) las been used to describe these "knowledge-based social structures made up of individuals who share a common interest or concern and who deepen their knowledge by interacting on an ongoing basis" (Wenger, McDermott, $\&$ Snyder, 2002, p. 1). The theoretical frame of CoP informed the present examination of learning and community building by individuals with disabilities using social media.

Today, the majority of Americans own some type of technology device; $73 \%$ of adults own a computer, $77 \%$ have a smartphone, 
and 53\% have a tablet (Pew, 2018). In addition, social media use is increasing at a rapid pace: The number of adults using social media grew from 7\% in 2005 to 69\% in 2018 (Pew, 2018). However, social media usage differs among different demographic groups. For example, whereas $88 \%$ of young adults age 18 to 29 commonly use social media, only a minority $(37 \%)$ of seniors age 65 and older participate (Pew, 2018). Some studies have examined social media use in particular demographic groups, for example, women (Asiodu, Waters, Dailey, Lee, \& Lyndon, 2015; Eckler, Kalyango, \& Paasch, 2016) and ethnic minority groups (American Press Institute, 2015; Harpin, Davis, Low, \& Gilroy, 2016); however, few studies have examined social media usage by individuals with disabilities.

Individuals with disabilities represent approximately $19 \%$ of the U.S. population-about 56.7 million people (Brault, 2012). Overall, $5 \%$ of Americans report an illness or condition that substantially limits their activities of daily living to the extent they require personal assistance (Brault, 2012). Furthermore, the American population is aging at an unprecedented rate and projected to double to more than 89 million by 2050 (Jacobsen, Kent, Lee, \& Mather, 2011). Severity and frequency of reported disabilities tends to increase with age such that $70.5 \%$ of individuals aged older than 80 report at least one disability (Brault, 2012). Together, these statistics suggest that not only do people with disabilities represent a significant proportion of the U.S. population, their number will increase over the next several decades.

Individuals with disabilities often encounter challenges in establishing social relationships and sustaining connections to their community. Social and physical barriers often make it difficult for people with disabilities to mobilize, hear, or understand others, to speak, or to communicate (Stough, Sharp, Resch, Decker, \& Wilker, 2015). Studies report people with disabilities tend to have smaller social circles, are often socially isolated, and have few friends outside of family members or paid service providers (Myers, Ager, Kerr, \& Myles, 1998; Robertson et al., 2001). In addition, stigma is still attached to disability and can create distance between people with disabilities and others (Smart, 2016). Together, these obstacles can contribute to the exclusion of people with disabilities from their communities and limit their access to information.

With the rise of Information and Communication Technologies (ICT; see Baker, Bricout, Moon, Coughlan, \& Pater, 2013; Cole, Nolan, Seko, Mancuso, \& Ospina, 2011), social media has become a primary source for creating community. Researchers note the critical importance of connecting individuals with disabilities to their communities (e.g., Cole et al., 2011; Dolphin, 2011) and social media promises social networking solutions for individuals with mobility impairments or who use alternative forms of communication (e.g., Cole et al., 2011; Hynan, Murray, \& Goldbart, 2014). The "connection-making" attribute of social media also supports learning and the sharing of information (Siemens, 2005). However, there has been a lack of research on how individuals with disabilities engage in social media (e.g., Cook \& Polgar, 2015), including how they use it for learning or connecting with others

\section{2 | METHOD}

The purpose of this systematic review was to understand how individuals with disabilities use social media for sharing knowledge and creating online communities. First, search terms related to specific social media platforms (e.g., Facebook and YouTube) previously used by Smith (2012) were selected. The search phrase "social media" used within EBSCO, ProQuest, ScienceDirect, and JSTOR databases, produced 116,731 articles. Two other search terms were added "individuals with disabili*" (produced 70,272 "es) and "disabili* service groups" OR "individuals with disabili" ${ }_{\text {wr }}$ oduced 48,067 articles). Based on the results, the search terms were narrowed to phrases such as "disabili* service groups" "- articles) and "disabili* service groups" OR "individuals with disabi.....ND "social medi $=35$ articles).

Next, we searched "individuals with disabili using the boolean term "AND" with the following social medias: "YouTube" (28), "Facebook" (56), "Google+" (105), "Skype" (15), "Shazam" (0), "Ortsbo" (0), "Linkedln" (6), "Badoo" (0), "Tumblr" (1), and "Twitter" (26). Independent searches were conducted within EBSCO, ProQue t; ScienceDirect, and JSTOR using the phrase "individuals with disabili"*. After duplicates were deleted, 573 articles were reviewed. Articles not directly related to individuals with disabilities and social media were excluded.

The first and second authors created codes to review the remaining 215 articles. First, the articles were coded as to whether they indeed related to social media and individuals with disabilities. The first and second authors then independently coded all articles by title and abstract in EBSCO, ScienceDirect, and ProQuest. Excluded from the search were terms such as blogsphere, web homepages, blogs, Internet, and Second Life. An 82\% inter-rater agreement was reached on the first step of coding for article relevance. The remaining articles were reviewed and discussed until 100\% agreement was reached. As a result, 29 of the 215 articles were potentially relevant. These 29 articles were reviewed independently by the first and second authors. Of the 29 reviewed articles, 14 were peer-reviewed research studies, 10 were popular literature, 1 was a conference paper, and 2 were theoretical papers. Although no date limit was placed on the search, the resultant articles had publication dates ranging from 2006 to 2015.

Each article was categorized by the first two authors using general content analysis (Mclntosh \& Cuklanz, 2017), which allowed for a systematic analysis of the data set. The first review resulted in six themes: community with subthemes friendship building, social support groups, and identity; cyberbullying, self-esteem, self-determination, access to technology, and accessibility. To confirm these civ categories, we conducted a second literature se Using the $t \epsilon \cdot \overline{\bar{p}}$ disabili* AND social media", and "social network $\overline{\bar{A}}$ D disabili*" between 2006 and 2015 in EBSCO, Scopus, and Web of Science yielded an additional 101 articles. From the 101 articles, 87 fit the inclusion criteria and 47 were omitted as they did not fit the purpose for this review (e.g., not specific to social media usage) or were not obtainable (e.g., written in a different language; unpublished). The remaining 40 articles were reviewed and categorized. An additional 10 articles were omitted as they were intervention studies. A total of 59 articles were read and reviewed. Two 
new subthemes (advocacy and information) emerged within the category of community.

\section{3 | RESULTS}

The following six themes emerged from our categorical analysis: community, cyberbullying, self-esteem, self-determination, access to technology, and accessibility.

\section{1 | Community}

Overall, the analysed studies predominantly focused on the demographics of individuals using social media platforms (e.g., age, gender, or disability type) and who connected with whom (e.g., individual to individual, individual to communities, or communities to communities). Community was a major theme found across these studies with a total of 29 articles forming this theme. Community referred to a group of individuals coming together with shared experiences, needs, and ideas (see Cole et al., 2011). Communities offe $\overline{\bar{a}}$ ( ommon space for members to gather for collaboration, support, advocacy, and identity development. Siemens (2005) argues "meaning-making and forming connections between specialized communities" (para. 17) supports the learning process. Five subthemes were found within the overarching theme of community: friendship building, information, social support groups, identity, and advocacy.

\subsection{1 | Friendship building}

Friendship building, particularly through Facebook, was a prominent theme for several researchers. Through semistructured interviews and observations of participant postings on Facebook, Hall (2011) explored social media interactions of five high school students with autism spectrum disorder (ASD). Participants reported Facebook as their primary social media tool due to ease of use, security, safety, visibility, and usage by family and friends. Hall found students with ASD were able to initiate contact with friends over social media easier than in person.

Similarly, Hashemy (2011) examined how 17 secondary students with ASD used various social media outlets through an online survey. Hashemy found students with ASD primarily used social media to stay in contact with friends/family or to create new friendships. The majority of students used social media for finding information or to communicate with others. Of students who engaged in social media, $100 \%$ used YouTube, 75\% used Facebook, 75\% used online instant messaging, and 19\% used Twitter (Hashemy, 2011). Both Hall (2011) and Hashemy (2011) noted the prevalent use of Facebook by secondary students for connecting with friends.

Asbjørnslett, Engelsrud, and Helseth completed two studies (Asbjørnslett, Engelsrud, \& Helseth, 2012, 2015) in which they interviewed children with disabilities between the ages of 12 and 14 . In the 2012 study, children found connecting with friends on Facebook allowed for easier communication once they encountered the same friend in person. Children used Facebook to keep up with or connect with their friends, to communicate with friends from other schools, or to join fan clubs. The authors observed "... Facebook provided an opportunity to start conversations and get to know others better ..." (Asbjørnslett, Engelsrud, \& Helseth, 2015, p. 326) thus leading to community building.

Shpigelman and Gill (2014a) explored how 172 adults with disabilities perceived and used Facebook. Participants were primarily college educated, employed, white, U.S. women reporting having a physical or mobility disability. Nearly half of the participants (48\%) were members of online disability groups (Shpigelman \& Gill, 2014a). Interestingly, adults with sensory, cognitive, communication, intellectual, or mental health disabilities were found to use Facebook less than participants with physical or mobility disabilities (Shpigelman \& Gill, 2014a). Overall, results revealed people with disabilities behaved similarly on Facebook to those without disabilities, namely, communicating with others, especially people they knew personally (Shpigelman \& Gill, 2014a).

In another study, Shpigelman and Gill (2014b) examined Facebook use by adults with intellectual disabilities $(n=58)$ through a self-report online survey. The majority of participants (82.8\%) used Facebook to connect with family and friends. Gaming and promoting their professional network were also indicated by the participants. The researchers distinguished between those using Facebook on their own and who needed assistance. Participants who used Facebook on their own tended to ask for help from others, chatted with friends, and looked for people they knew. Participants also indicated it was easier to make friends or chat with people on Facebook than in person. A quarter of participants commented they felt they were "like everyone else" (p. 1608) when on Facebook.

Holmes and O'Loughlin (2014) completed a study with three middle-aged women with learning disabilities, including one with autism. Participants discussed how Facebook was a way to connect with others, to share their thoughts, and to have a wider social network. Safety concerns included issues such as sexual exploitation, fraud, and attending community events when invited by any "friends."

Rasid and Nonis (2015) interviewed and surveyed nine 14- to 18-year-old adolescents with cerebral palsy about their social media and device type usage (smartphones, tablets, laptops, and desktops). Social media sites included Facebook, YouTube, Instagram, Twitter, and WhatsApp. The participants primarily communicated with peers and volunteers from their school to make plans to meet up outside of school. Twenty-eight percent of the participants found social networking as a way to overcome social and environmental barriers. Four participants used social networking to meet people through the sites. An additional four participants disclosed their disability to others on social networking sites. Six participants used social networking sites to read "new updates on friends via newsfeed, chat and play online games" (p. 24). A few participants declared social media "... enabled them to seek emotional support and to share their feelings" (p. 24). The participants reported awareness of social media use dangers, including choosing who to talk with, who to meet in person, and personal identifying information revealed online. The researchers concluded social media assisted adolescents in 
establishing friendships, expanding their social networks, and providing emotional support.

\subsection{2 | Information}

A primary use of social media in these studies was to give or receive information. Information was also shared to help communicate with doctors. Forums and blogs were described as a method through which to search and gain information.

Annett-Hitchcock and Xu (2015) studied shopping patterns and virtual communities of individuals with physical disabilities using participants' comments to forums on a website. Participants mentioned social media sites and tools such as Facebook, Google, blogs, and text messaging within these forums and described including weblinks and pictures to share information.

Marrie, Salter, Tyry, Fox, and Cutter (2013) studied the responses of 8,586 individuals with multiple sclerosis (MS) on how they sought information about MS. Some participants used the Internet for online support groups, ordering health materials, blogging, and social networking. The authors noted that

"the Internet, including social media, provides a means for rapid dissemination of health information by health care providers, which can be readily updated. However, it is crucial this information be provided in a way that is readily accessible and comprehensible to people of all socioeconomic backgrounds" (para 25).

The study illustrates how individuals with disabilities may use social media to learn more information about their disability.

Griffiths et al. (2012) discussed ways social media assisted individuals with disabilities in sharing information with their doctors or to build community. Individuals with disabilities with rare conditions, in particular, used Twitter, Facebook, and MySpace to build community. The researchers noted "for rarer conditions, online social networking can be the only means for geographically scattered populations to interact and share knowledge about their condition" (p. 2236). However, the authors also pointed out limitations in sharing confidential medical information.

Hemsley, Dann, Palmer, Allan, and Balandin (2015) completed a mixed methods study on Twitter use by five individuals who used augmentative and alternative communication devices. Participants used Twitter for 2 to 5 years and had an average of 116 followers. Participants who used augmentative and alternative communication valued Twitter as they felt visible, seen, and heard. The authors noted

Twitter can be used as an important vehicle for conversation and a forum for people with communication disabilities to exchange information and participate socially in online communities. It is important that information and resources relating to the effective use of Twitter for a range of purposes are made available to people with communication disabilities who wish to take up or maintain use of Twitter. People with communication disabilities might benefit from support in using Twitter to meet their goals relating to participation in online forums and information exchange (p. 1531).

\subsection{3 | Social support groups}

Social support groups were found as another way to build community. Davis and Calitz's (2014) completed a literature review of studies of online communities, particularly virtual worlds, to view efficacy of online support groups. The authors suggest online support groups, either through the Internet or virtual worlds, could assist in building community and sharing informatio $\ldots$ ong people with disabilities. Individuals who were chronically $\mathrm{i} ., \ldots$.... nded to participate in virtual worlds. The researchers found social support groups offered emotional and moral support among people with disabilities.

Cole et al. (2011) used narrative inquiry to examine 12 years of digital archives from the GimpGirl Community (GGC), as well as autoethnographic reflections from Jennifer Cole (founding member of GGC). The digital archives included "postings to the community listservs, blog entries, minutes from staff meetings, and online dialogues among the members" (p. 1164). The GGC used virtual worlds as a space to create community. The community was originally established as a place by young women with disabilities who chose the online world as a way to shift the "discourse from an institutional/medical location to a community of their own" (p. 1174). As the community grew, it expanded to include adult women with disabilities and "participants expressed a sense of commonality, acceptance, and empowerment" (p. 1168).

Email and LiveJournal platforms were the initial media spaces for the GGC. Then, to increase outreach, the GGC expanded to Facebook, MySpace, Twitter, Moodle-based website, and wikis. However, Facebook and MySpace were later removed due to usability issues and resultant inactivity by members with disabilities in the community (Cole et al., 2011). In sum, researchers found "by using a variety of online tools, the GGC helped members develop capacity to perform as agents of self- and social transformation" (p. 1174).

In another social support study, Bromley (2008) categorized YouTube videos containing disability-related content. A total 147 YouTube videos were classified using the 13 categories of disability as defined in the Individuals with Disabilities Education Act (1997). The majority of videos either addressed deafness $(n=70)$ or autism $(n=58$ ). The authors sorted YouTube videos by content type (i.e., personal story, news clip, advertisement, instructional, and public service). The most common type of videos were vlogs (26\%), followed by either personal stories from parents (15\%) or individuals (12\%). Approximately half of the videos within the deaf community were vlogs. The authors suggest the relatively high rate of participation by the deaf community on YouTube is due to the historically established culture of the group and to the nature of video as a visual communication form. The large number of videos about autism were attributed primarily to two-member-created projects focusing specifically on autism. The authors note although YouTube contains both noteworthy 
videos about disability and has considerable educational value, users searching for disability-related content "should be prepared to sift through the irrelevant, the distasteful, and the inaccurate in order to find the gems" (p. 12).

Baker et al. (2013) used disability and aging key terms to analyse groups found on Linkedln and Facebook. After examining 2 weeks of social media data, the authors found participants used both Linkedln and Facebook for social, business, or professional purposes. For employment, Linkedln was used more than Facebook.

Kirby, Edwards, and Hughes (2008) collected data from postings on the Dyscovery Centre message boards. The Dyscovery Centre "... is a specialist assessment and training centre, based at the University of Wales, Newport ..." (Kirby et al., 2008, p. 194). The majority of postings were from parents of children with developmental disorders. The researchers identified themes, such as asking for help, asking questions, or being happy to find someone to talk with. Posting to forums appeared to contribute to a sense of community on the Dyscovery Centre's message board.

Social media includes chat rooms. Mazurek, Shattuck, Wagner, and Cooper (2012) studied a national sample of parent interviews on youth screen use. Youth with ASD were compared to youth with intellectual, speech/language, and learning disabilities from parent interviews. Less than half of the youth with ASD used chat or email. In contrast, participants with learning and speech/language disabilities used chat and email twice as much as did youth with ASD (Mazurek et al., 2012). The authors declared "specifically, we found that youths with ASD who had poorer overall functional cognitive abilities and poorer conversational skills were less likely to use email or participate in chat rooms than those with no conversational or cognitive difficulties" (p. 1765).

In addition to Twitter, Seale (2013) found Facebook served to connect and provide community support for individuals. University students with disabilities (primarily dyslexia) reported using Facebook in groups for classwork and support. Similarly, Valcourt-Pearce (2015) used Facebook to report her own experiences with her child who was born deaf and with multiple disabilities. $\overline{\text { Val }}$ ourt-Pearce revealed how Facebook helped connect her with other families with children with similar disabilities.

Shoham and Heber (2012) completed a content analysis on a forum used by $d /$ Deaf (10\%) and hard of hearing (72\%) individuals in Israel. Topics in the forum included difficulties (e.g., physical, emotional, and medical), social activities, meeting people, finding friends, giving greetings such as "happy birthday," rights, employment (e.g., advertisements), technical aspects (e.g., hearing aids), recommendations of professionals, deafness and hearing loss research or media, sign language, participant blogs, and news. Interestingly, forum participants tended to give social support rather than asking for social support.

Stack-Cutler, Parrila, Jokisaari, and Nurmi (2015) studied 107 college students completing or who had just completed their degree and also had reading difficulties. Thirty-two participants (29.9\%) noted they used social media networking, including Facebook, chat forums, email, and other social media networking sites. Twenty-two participants used social media to contact family and friends, whereas three participants found emotional support or "encouragement from friends" (p. 327) on social media. Social networks were used for participants to gain school-related information, problem solve, have questions answered, receive emotional support, or seek goal acknowledgement.

\subsection{4 | Identity}

Identity as a theme occurred both in studies on individual identity or organizational/community identity. Dolphin's (2011) thesis focused on identity development for people with disabilities. Specifically, she explored how people with disabilities constructed individual and community identities through user-generated media on sites such as YouTube. Dolphin (2011) stated when people with disabilities constructed their own identities through user-generated materials, the material challenged "the societal constructs of disability ..." (р. 79). YouTube, in particular, was used by people with disabilities to disrupt power structures and to establish communities of support. For example, the author reported that, instead of the typical medical discourse occurring on mainstream media, sites such as YouTube provided a space for people with disabilities to establish different identities.

Noble (2012) examined cyberspace use by nine disability-related organizations in the Philippines. Noble coded the websites of the nine organizations and interviewed staff members from five of the organizations about "... discourse, publication, development, and back operations ..." (Noble, 2012, p. 35). Facebook, YouTube, and blogs were used by these organizations to reach out to people with disabilities. Noble found cyberspace permitted people with disabilities to have a "virtual social identity" (p. 161) paralleling their "actual social identity" (p. 161) as a way to communicate and maintain social and professional relationships. Additionally, cyberspace allowed impression management in building social networks and relationships. The author suggests social media facilitates access to social relationships not accessible otherwise.

\subsection{5 | Advocacy}

Social media was used to advocate. Pearson and Trevisan (2015) completed a content analysis over TV and print media in London for one week following the Paralympic games in 2012, specifically studying an activist group Disabled People Against Cuts (DPAC). The content analysis examined how DPAC advocated through TV and print media following the games in London.

"Whilst DPAC's approach to online media prior to the Paralympics allowed them to retain full control over communications, the interest from traditional news outlets during the Games enabled a strengthening of their message and more positive images of disability to be promoted"

(Pearson \& Trevisan, 2015, p. 937). The authors noted "since the outset of the austerity programme, platforms such as blogs, Twitter and Facebook have proved important tools for disability activism in challenging government policy" (p. 928). 
Wright and Taylor (2014) gave a questionnaire through social media to parents of children with special needs. Of the 76 participants with children from birth to age 6,51\% indicated social media as a place for advocacy and $13 \%$ indicated social media was a "highly effective" (p. 597) way to advocate. Two social media sites mentioned were Facebook and Caringbridge. Sharing occurred through pictures, their history, advocating, and showing people how their child was like anyone else. Social media was thus used to "de-stigmatize" and to connect "... with other families who have children with the same diagnosis" (p. 20). Social media also allowed participants to connect with other families to give and receive support. Chiu and Juang (2013) similarly completed a content analysis on the use of Facebook. After analysing 49 pages, they determined "awareness raising" (p. 383) was the most common use of fan pages for children with disabilities.

Community was evidenced through posts and comments on YouTube videos related to the chronic cerebrospinal venous insufficiency "liberation" procedure (Mazanderani, O'Neill, \& Powell, 2013). The authors categorized the 100 most viewed YouTube videos on this topic. Patients showed before and after videos of physical limitations and how limitations changed after the liberation procedure. In videos and comment postings, patients related medical knowledge, discussed certain doctors, or views/opinions of the procedure. Similarly, Libin et al. (2011) completed a content analysis on YouTube videos for spinal cord injuries. 'lev ers found content more accessible when the YouTube content verng demonstrated involved a task the individual watching wanted to accomplish (Libin et al., 2011).

In sum, within the theme of community, social media was used by people with disabilities for friendship building, identity development, and general social support. A primary finding was that some people with disabilities (i.e., ASD) sometimes preferred social media over in-person contact.

\section{2 | Cyberbullying}

Although social media provides a way for people to build relationships, it can be a venue for cyberbullying. Two articles discussed cyberbullying. Kowalski and Fedina (2011) studied the health effects of cyberbullying on youth with attention deficit hyperactivity disorder or Asperger's syndrome. In this study, researchers surveyed 42 students between ages 10 to 20 years old and their parents. Participants reported instant messaging and social networking sites were the most prevalent places for cyberbullying. Additionally, Kowalski and Fedina found perpetrators of the cyberbullving were either friends or other students at the school. Surprisingly, 1 nev noted that, among the parent participants "seventy-three percent said that their child had never been cyber bullied" (p. 1205).

Some advocates have noted the safety issue of social networking for people with disabilities and established safe and moderated social networking sites, such as the United Kingdom-based "People \& Places" for people with learning disabilities (Marshall, 2011). These serve as alternatives to traditional social networking sites. The GGC (Cole et al., 2011), previously discussed, is another example of a social media community for a specific group of people (i.e., women with disabilities). Overall, the popularity of social media use combined with the potential vulnerability of youth with disabilities makes it critical that the prevalence of cyberbullying is understood by users and their parents. Kowalski and Fedina (2011) noted cyberbullying awareness and interventions may be particularly important for children with disabilities as they may prefer online interactions over face-to-face interactions. Given the limited results from our literature search, we suggest cyberbullying is a critical area for more research.

\section{3 | Self-esteem}

Self-esteem was a theme in two reviewed articles. Hill (2014) examined the self-esteem of 56 students with cognitive or intellectual disabilities in relation to their Facebook use. Students completed surveys including the Facebook Intensity scale and the Rosenberg Self-Esteem scale. Hill found no relationship among disability, social networking, and self-esteem. However, Hill (2014) did find "those students who spend more time on Facebook tended to have lower self-esteem than those who use it less often" (p. 42).

\section{4 | Self-determination}

Three articles related to self-determination. Self-determination refers to an individual's perception of having the ability to access information independently and having increased privacy (Hynan, Goldbart, \& Murray, 2015). Hynan et al. (2014) found teenagers with disabilities highly motivated to be online. Some participants were able to use social media individually, whereas other participants relied on assistance from other people. Participants used Skype, MSN, or Facebook most frequently. Participants described using Facebook for "self-representation," adding pictures, thoughts, and sharing through timelines and Facebook page personalization. Participants expressed higher selfdetermination with shopping online and making schedules (Hynan et al., 2014).

Caron and Light (2015) completed a focus group on social media use with seven individuals with amyotrophic lateral sclerosis (ALS). Participants reported social media as a beneficial tool providing increased communication opportunities, connections to communication partners, and networks of support. The researchers described how "as individuals with ALS experience loss of function, some communication modes may no longer be viable. Providing access to different modes of communication, including social media, can allow independence, participation and better quality of life" (p. 680).

Paterson and Carpenter (2015) videotaped seven male adults with neurological disorder as well as speech and language impairments in a hospital rehab setting in the United Kingdom. Participants had difficulties being verbally understood by others and had used an augmentative and alternative communication device for 6 months. Participants reported preferring email communication as it gave time to think about responses, edit, or correct responses. Participants indicated Skype, Facebook, and Twitter messaging allowed for increased 
communication ease as it gave them the ability to keep up with conversations in comparison to talking face-to-face. The researchers found participants who used social media or email before were more likely to use it after their speech loss.

\section{5 | Access to technology}

Access to technology refers to owning or using technological devices (i.e., tablet, smartphone, and computer) capable of accessing various social media platforms. Within three of the reviewed articles, limited access to technology was a common concern. Limited access to social media may be associated with the high cost of technology hardware or software. Adults with disabilities typically earn less than adults without disabilities and are more likely to live in poverty when compared to the general population (Brault, 2012; Kraus, Lauer, Coleman, \& Houtenville, 2018).

Noble (2012) observed difficulties participants had in obtaining hardware for use with social media, noting some individuals in his study were dependent on organizations to provide the necessary hardware and devices. Dolphin (2011), similarly noted people who live in poverty, who are elderly, or who have a disability often experienced the least access to computer/technology-based resources. Cole et al. (2011) noted the digital divide, uneven access to ICT, and the necessity of exploring "what people actually do with ICTs, rather than investigating access issues" (p. 1162). To participate in social media communities, individuals with disabilities first must obtain access to technology, such as computers or smartphones.

\subsection{Accessibility for individuals with disabilities}

Accessibility refers to how social media sites are designed to promote ease of navigating social media sites, particularly by individuals who use assistive technology devices. Seven articles discussed accessibility concerns. The World Wide Web Consortium's Web Accessibility Initiative described web accessibility as allowing individuals with disabilities to "perceive, understand, navigate, and interact with the Web, and that [the individuals] can contribute to the Web" (World Wide Web Consortium, 2005). When a social media platform does not meet accessibility standards, people with disabilities may not be able to use that platform, even while having access to the Web. Application of guidelines or technical standards by web designers and developers that makes web content more accessible for individuals with disabilities (see World Wide Web Consortium, 2012) increases the likelihood individuals with disabilities will be able to navigate and use information available on the site.

Ellis and Kent (2011) discussed accessibility issues with the Internet, especially with the use of Captcha with audio, drop-down boxes, font sizes, and Facebook. For example, MySpace did not have an accessibility policy and had issues with Captcha for signing up. However, the authors also noted "internet-based technologies have the potential to offer greater inclusion to people with disability, and are often presented as a way to eradicate socially constructed disability" (p. 97).

In addition to findings on friendship building, Hashemy (2011) found students with ASD had accessibility problems when using social media. Accessibility problems included "program downloading, accessing information websites, loading videos, and connectivity" (p. 39). Other concerns included difficulties in designing events/commentary, entering the site, and following commentary or problems accessing "graphics or videos shared on the Blogs" (p. 59). Overall, students with ASD evidenced struggles or limitations when using social media, while also valuing that social media helped to connect them to friends and family.

In Shpigelman and Gill's (2014b) study, 45 of 58 participants with intellectual disabilities found Facebook accessible, although they indicated a need for less text, choice for speech to text, and suggested an online help for users. Participants "... perceive Facebook as an inaccessible and unsafe environment that should be accommodated to their needs" (Shpigelman \& Gill, 2014b, p. 1610). Participants did not like how Facebook changed and updated frequently.

Magee (2012) tested the Hierarchical Adaptive Interface Layout software. Researchers examined how participants could use the simple response system to answer questions on Twitter. For example, participants could give answers about their day or activities through a smiley face chart or pre-made question drop-down list. These modifications provided participants with limited mobility with an adapted way to post on Twitter. Second, Magee (2012) studied the use of a mouse pointer with a head-tracking device for individuals with severe limited mobility and found adaptability of screen set-up for specific users. Magee noted when individuals required personal assistance to use social media this limited the privacy of their communications. In addition, in such cases, personal assistants must also know how to use social media but may not have the time or interest to do so.

\section{4 | DISCUSSION}

Our systematic literature review identified six major themes pertaining to social media use by individuals with disabilities: community, cyberbullying, self-esteem, self-determination, access to technology, and accessibility. Caton and Chapman (2016), in a literature review on social media use by individuals with intellectual disabilities found intersecting themes including; support, identity, behaviour on cyberspace, and accessibility. We found most studies focused on how individuals with disabilities used social media tools to create community or to obtain information. The majority reported positive aspects of social media use such as building knowledge, forming friendships, and creating social support groups. The social support networks of people with disabilities have been a concern of disability scholars for some time now (e.g., Nisbet, 1992; Stough, Ducy, \& Holt, 2017; Wilson, Washington, Engel, Ciol, \& Jensen, 2006). Findings from this review suggest social media tools can effectively support positive social networks and knowledge exchange for people with disabilities. 
However, a more complex picture of social media use also emerged from our analysis. First, to participate in social media, individuals with disabilities must be able to afford technology (for example, computers, cell phones, and software). However, individuals with disabilities often have low incomes or live in poverty (Brault, 2012; Kraus, Lauer, Coleman, \& Houtenville, 2018); therefore, acquiring a computer, smartphone, or other electronic device to use social media may not be financially feasible. Second, adaptability of devices, such as a mouse pointer with a head-tracking device as described by Magee (2012), addresses accessibility barriers, but can add additional costs. Even public devices such as computers at libraries may pose limits if not adaptable. Third, social media platforms must be accessible to those using it. The Americans with Disabilities Amendments Act (ADA) standards for accessible design state all electronic and information technology must be accessible to people with disabilities, including websites (2008). However, the principle of universal access is still not implemented in some cyber environmentsincluding many social media platforms. As we have already noted, low-income levels can limit Internet usage (Perrin \& Duggan, 2015). Although many researchers suggest technology as a solution to the barriers individuals with disability face, others point out social media platforms actually create accessibility barriers. Foley (2006) suggests that although the Internet has increased the ways in which people can communicate, it also can increase isolation for people who do not have access to technology. He further notes "access is not about the 'limitations' of the individual; rather it is about society's inability to accommodate difference" (2006, p. 249). Thus, barriers to social media can exist even before people with disabilities engage with a social media platform.

\section{1 | Towards a reconceptualization of social media use by individuals with disabilities}

As social media becomes more ubiquitous, research on effective and positive social media practices become more important. The concept of CoP has been used in educational contexts as a framework for discourse communities to develop and share knowledge (Wenger et al., 2002). To be considered a CoP, three structural elements must exist: domain, community, and practice.

Domain is the "common ground" and sense of identity among participants in the community (Wenger et al., 2002). Each of the studies referenced in this paper shared a different domain. The domain in Hall (2011) included students with ASD. The domain examined by Marrie et al. (2013) included individuals with MS. The GimpGirl domain included girls and women with disabilities (Cole et al., 2011). Of note is that a domain does not simply consist of participants who share particular qualities but rather "the identity defined by a shared domain of interest" (Wenger-Trayner \& Wenger-Trayner, 2015, para. 5).

The element of community inspires trust and interaction among the members. It supports the opportunity to ask questions, share experiences, and give support. In studies of these groups, individuals with disabilities built community by creating support groups (e.g., Cole et al., 2011; Davis \& Calitz, 2014), cultivating identity (Dolphin, 2011; Noble, 2012), and building friendships (e.g., Hall, 2011; Hashemy, 2011). Participants in these groups felt a "sense of belonging," which is critical to the element of community (Wenger et al., 2002).

Practice refers to the specific knowledge developed, shared, and maintained within a social networking community. In Shoham and Heber (2012), types of specific knowledge shared included the physical, emotional, and medical difficulties associated with having a disability as well as disability rights and employment opportunities. In Stack-Cutler et al. (2015), practice centred around strategies for addressing reading difficulties-information related to schools, problem solving, and emotional support. In Griffiths et al. (2012), the individuals shared information with their doctors and built community. The resources, ideas, and stories such as those shared in these groups constituted the practice or the knowledge the community develops and maintains (Wenger et al., 2002).

Different social media tools (e.g., blogs and Twitter) are assumed to encourage different types of knowledge creation and sharing. For example, the GGC uses blogs, Twitter, and virtual worlds to discuss women and disability issues (Cole et al., 2011), whereas Dolphin (2011) found individuals with disabilities used video-based social media tools, such as YouTube. Technology not only supports the ability to connect socially but also gives researchers the opportunity to capture how the practice is shared among users. Understanding this practice can inform social media platform design. When a designer understands the goal of a particular community is to share information with medical professionals, the designer can implement tools to streamline this process, such as video chat or secure email exchange. The quality of the online system, the quality of the information itself, and social information exchange have been shown to enhance the sense of virtual community among members using social networking sites (Chen \& Lin, 2014). The use of CoP as a framework to analyse online interactions can thus assist researchers in understanding how particular social media tools are used by the community of users. As a result, strategies aimed at enhancing online system quality and information quality and information exchange can be designed to capitalize on the strengths of the community, minimize concerns, and effectively share knowledge, to enhance community through practice.

Domain represents the space where individuals share their thoughts and ideas regarding the particular topic. Social media tools such as Facebook, Twitter, and YouTube support these virtual spaces. When the three elements of domain, community, and practice "...function well together, they make a CoP an ideal 'knowledge structure - a social structure that can assume responsibility for developing and sharing knowledge'" (Wenger et al., 2002 p. 29 as cited in Gunawardena et al., p. 6). Understanding interactions within and across CoP structural elements can assist researchers in designing ideal structures and, as a result, greatly enhance the learning experience of communities. 


\section{5 | CONCLUSION}

Additional research is necessary to inform the development and design of social media that is inclusive for all people. Such research will become more necessary as ICT continues to grow, with social media as a leading communication pathway. In addition to access to new social opportunities, such as collaboration, advocacy, and support, as described by studies in this review, social media also supports information sharing and knowledge sharing-vital skills for today's learner. However, if individuals are not able to actually use social media tools, this benefit is lost and can lead to further marginalization and isolation. Poorly designed social media, creates barriers for people with disabilities. Through systematically examining and refining aspects of community, domain, and practice virtual spaces using social media tools can be created to support the needs of individuals with disabilities and reduce negative effects. Ensuring equitable access to technology, particularly social media tools, allows individuals with disabilities to take advantage of the benefits social media can provide, such as collaboration, knowledge building, information sharing, and advocacy (Cifuentes et al., 2009). People with disabilities have the right to be included in the revolutionary change in social networking that social media can provide-but that change needs to be accessible.

\section{ORCID}

Kayla S. Sweet (D) https://orcid.org/0000-0002-9180-7410

Laura M. Stough (D) https://orcid.org/0000-0002-0313-5045

Noelle W. Sweany (D) https://orcid.org/0000-0003-1279-7320

\section{REFERENCES}

American Press Institute. (2015, August 21). Race, ethnicity, and the use of social media for news. Retrieved from https://www. americanpressinstitute.org/publications/reports/survey-research/raceethnicity-social-media-news/

Americans With Disabilities Amendments Act of 2008, Pub. L. No. 110325, 122 Stat. 3553 (2008)

Annett-Hitchcock, K., \& Xu, Y. (2015). Shopping and virtual communities for consumers with physical disabilities. International Journal of Consumer Studies, 39(2), 136-144. https://doi.org/10.1111/ijcs.12161

Asbjørnslett, M., Engelsrud, G. H., \& Helseth, S. (2012). "Friendship in all directions": Norwegian children with physical disabilities experiencing friendship. Childhood: A Global Journal of Child Research, 19(4), 481-494. https://doi.org/10.1177/0907568211428093

Asbjørnslett, M., Engelsrud, G. H., \& Helseth, S. (2015). How children with disabilities engage in occupations during a transitional phase. Journal of Occupational Science, 22(3), 320-333. https://doi.org/10.1080/ 14427591.2014.952365

Asiodu, I. V., Waters, C. M., Dailey, D. E., Lee, K. A., \& Lyndon, A. (2015). Breastfeeding and use of social media among first-time African American mothers. JOGNN: Journal of Obstetric, Gynecologic \& Neonatal Nursing, 44(2), 268-278. https://doi.org/10.1111/1552-6909.12552

Baker, P. M. A., Bricout, J. C., Moon, N. W., Coughlan, B., \& Pater, J. (2013). Communities of participation: A comparison of disability and aging identified groups on Facebook and LinkedIn. Telematics and Informatics, 30, 22-34. https://doi.org/10.1016/j.tele.2012.03.004
Brault, M. W. (2012). Americans with disabilities: 2010 Household Economic Studies. Current Population Reports (P70-131). Retrieved from https:// www.census.gov/prod/2012pubs/p70-131.pdf

Bromley, B. E. (2008). Broadcasting disability: An exploration of the educational potential of a video sharing web site. Journal of Special Education Technology, 23(4), 1-13. https://doi.org/10.1177/ 016264340802300401

Caron, J., \& Light, J. (2015). "My world has expanded even though I'm stuck at home": Experiences of individuals with amyotrophic lateral sclerosis who use augmentative and alternative communication and social media. American Journal of Speech-Language Pathology, 24(4), 680-695. https://doi.org/10.1044/2015_AJSLP-15-0010

Caton, S., \& Chapman, M. (2016). The use of social media and people with intellectual disability: A systematic review and thematic analysis. Journal of Intellectual and Developmental Disability, 41(2), 125-139. https://doi.org/10.3109/13668250.2016.1153052

Chen, C., \& Lin, C. (2014). Building a sense of virtual community: The role of the features of social networking sites. Cyberpsychology, Behavior, and Social Networking, 17(7), 460-465. https://doi.org/10.1089/ cyber.2013.0530

Chiu, M. -H. P., \& Juang, M. -J. (2013). A content analysis of Facebook pages for children with disability. Journal of Educational Media and Library Science, 50(3). https://doi.org/10.6120/JoEMLS.2013.503/ 0528.RS.CM

Cifuentes, L., Sharp A., N., Bulu, S., Benz, M., \& Stough L., M. (2009). Developing a Web 2.0-based system with user-authored content for community use and teacher education. Educational Technology Research and Development, 58(4), 377-398.

Cole, J., Nolan, J., Seko, Y., Mancuso, K., \& Ospina, A. (2011). GimpGirl grows up: Women with disabilities rethinking, redefining, and reclaiming community. New Media and Society, 13(7), 1161-1179. https://doi.org/10.1177/1461444811398032

Cook, A. M., \& Polgar, J. M. (2015). Technologies that assist people who have disabilities. In Assistive Technologies, Principles and Practice (4th ed.) (pp. 16-29). St. Louis, MO: Mosby.

Davis, D. Z., \& Calitz, W. (2014). Finding healthcare support in online communities: An exploration of the evolution and efficacy of virtual support groups. Journal of Virtual Worlds Research, 7(3), Lantern, (2). https://doi.org/10.4101/jvwr.v7i3.7068

Dolphin, D. (2011). Digital disability discourses: User-generated content, identity, and resistance. (Master's thesis). Retrieved from ProQuest Dissertations and Theses database. (UMI No. 1491454)

Eckler, P. P., Kalyango, Y., \& Paasch, M. E. (2016). Facebook use and negative body image among U.S. college women. Women And Health, 57(2), 249-267. https://doi.org/10.1080/03630242.2016.1159268

Ellis, K., \& Kent, M. (2011). Does that face-"book" come in braille? Social networking sites and disability. Disability and New Media, 7, 95-112.

Foley, A. (2006). Informing instructional technologies: Re-readings of policy, practice, and design. In S. Danforth, \& S. Gabel (Eds.), Vital questions facing disability studies in education (pp. 237-252). New York, NY: Peter Lang Publishing.

Griffiths, F., Cave, J., Boardman, F., Ren, J., Pawlikowska, T., Ball, R., ... Cohen, A. (2012). Social networks-The future for health care delivery. Social Science and Medicine, 75(12), 2233-2241. https://doi.org/ 10.1016/j.socscimed.2012.08.023

Gunawardena, C. N., Hermans, M. B., Sanchez, D., Richmond, C., Bohley, M., \& Tuttle, R. (2009). A theoretical framework for building online communities of practice with social networking tools. Educational Media International, 46(1), 3-16. https://doi.org/10.1080/ 09523980802588626 
Hall, C. M. (2011). Social networking and teens with autism spectrum disorder: A case study of online friendship. (Doctoral dissertation). Retrieved from ProQuest Dissertations and Theses database. (UMI No. 3464518)

Harpin, S., Davis, J., Low, H., \& Gilroy, C. (2016). Mobile phone and social media use of homeless youth in Denver, Colorado. Journal of Community Health Nursing, 33(2), 90-97. https://doi.org/10.1080/ 07370016.1159440

Hashemy, S. T. (2011). Usability and accessibility of social media among Canadians with high functioning autism. (Master's thesis, Library and Archives Canada, Montreal, Quebec). Retrieved from ProQuest Dissertations and Theses database.

Hemsley, B., Dann, S., Palmer, S., Allan, M., \& Balandin, S. (2015). "We definitely need an audience": Experiences of twitter, twitter networks and tweet content in adults with severe communication disabilities who use augmentative and alternative communication (AAC). Disability and Rehabilitation, 37(17), 1531-1542. https://doi.org/10.3109/ 09638288.2015.1045990

Hill, C. L. (2014). An investigation of the connections between use of Facebook and the self-esteem/well-being of students with disabilities in the University of lowa Reach Program. (Doctoral dissertation). Retrieved from ProQuest Dissertations and Theses database. (UMI No. 3638381)

Holmes, K. M., \& O'Loughlin, N. (2014). The experiences of people with learning disabilities on social networking sites. British Journal of Learning Disabilities, 42(1), 1-5. https://doi.org/10.1111/bld.12001

Hynan, A., Goldbart, J., \& Murray, J. (2015). A grounded theory of Internet and social media use by young people who use augmentative and alternative communication (ACC). Disability and Rehabilitation, 37(17), 1559-1575. https://doi.org/10.3109/09638288.2015.1056387

Hynan, A., Murray, J., \& Goldbart, J. (2014). 'Happy and excited': Perceptions or using digital technology and social media by young people who use augmentative and alternative communication. Child Language Technology \& Therapy, 30(2), 175-186. https://doi.org/10.1177/ 0265659013519258

Jacobsen, L. A., Kent, M., Lee, M., \& Mather, M. (2011). America's Aging Population, Population Bulletin 66, no. 1. Population Reference Bureau. Downloaded December 10, 2015 from http://www.prb.org/pdf11/ aging-in-america.pdf

Kirby, A., Edwards, L., \& Hughes, A. (2008). Parents' concerns about children with specific learning difficulties: Insights gained from an online message centre. Support for Learning, 23(4), 193-200. https://doi.org/ 10.1111/j.1467-9604.2008.00393.x

Kowalski, R. M., \& Fedina, C. (2011). Cyber bullying in ADHD and Asperger syndrome populations. Research in Autism Spectrum Disorders, 5, 1201-1208. https://doi.org/10.1016/j.rasd.2011.01.007

Kraus, L., Lauer, E., Coleman, R., Houtenville, A., \& University of New Hampshire, U. I. on D. (2018). 2017 Disability Statistics Annual Report. A Publication of the Rehabilitation Research and Training Center on Disability Statistics and Demographics. Institute on Disability, University of New Hampshire. Institute on Disability, University of New Hampshire. Retrieved from https://eric.ed.gov/?id=ED583258

Libin, A., Schladen, M. M., Ljungberg, I., Tsai, B., Jacobs, S., Reinauer, K., ... Groah, S. (2011). YouTube as an on-line disability self-management tool in persons with spinal cord injury. Topics in Spinal Cord Injury Rehabilitation, 16(3), 84-92. https://doi.org/10.1310/sci1603-84

Magee, J. J. IV. (2012). Adaptable interfaces for people with motion disabilities. (Doctoral dissertation). Retrieved from ProQuest Dissertations and Theses database. (UMI No. 3483494)

Marrie, R. A., Salter, A. R., Tyry, T., Fox, R. J., \& Cutter, G. R. (2013). Preferred sources of health information in persons with multiple sclerosis: Degree of trust and information sought. Journal of Medical Internet Research, 15(4), e67. https://doi.org/10.2196/jmir.2466

Marshall, D. (2011). Bringing people together. Learning Disability Today, 11(6), 36-37.

Mazanderani, F., O'Neill, B., \& Powell, J. (2013). "People power" or "pester power"? YouTube as a forum for the generation of evidence and patient advocacy. Patient Education and Counseling, 93(3), 420-425. https://doi.org/10.1016/j.pec.2013.06.006

Mazurek, M. O., Shattuck, P. T., Wagner, M., \& Cooper, B. P. (2012). Prevalence and correlates of screen-based media use among youths with autism spectrum disorders. Journal of Autism and Developmental Disorders, 42(8), 1757-1767. https://doi.org/10.1007/s10803-011-1413-8

Mclntosh, H., \& Cuklanz, L. (2017). Researching mass media: Images and texts. In S. Hesse-Biber (Ed.), The practice of qualitative research (3rd ed.) (pp. 246-271). SAGE: Thousand Oaks, CA.

Myers, F., Ager, A., Kerr, P., \& Myles, S. (1998). Outside looking in? Studies of the community integration of people with intellectual disability. Disability and Society, 13, 389-413. https://doi.org/10.1080/ 09687599826704

Nisbet, J. (1992). Introduction. In J. Nisbet (Ed.), Natural supports in school, at work, and in the community for people with severe disabilities (pp. 1-10). Baltimore, MD: Paul H. Brooks Publishing.

Noble, C. D. (2012). Cyberspace as equalizer: Opening up lifeworlds and empowering persons with disabilities in the Philippines. (Doctoral dissertation). Retrieved from ProQuest Dissertations and Theses database. (UMI No. 3520657)

Paterson, H., \& Carpenter, C. (2015). Using different methods to communicate: How adults with severe acquired communication difficulties make decisions about the communication methods they use and how they experience them. Disability and Rehabilitation, 37(17), 1522-1530. https://doi.org/10.3109/09638288.2015.1052575

Pearson, C., \& Trevisan, F. (2015). Disability activism in the new media ecology: Campaigning strategies in the digital era. Disability and Society, 30(6), 924-940. https://doi.org/10.1080/09687599.2015.1051516

Perrin, A., \& Duggan, M. (2015, June 26). American's Internet access: 20002015 as Internet use nears saturation for some groups, a look at patterns of adoption. Retrieved from http://www.pewinternet.org/2015/06/ 26/americans-internet-access-2000-2015/\#internet-usage-by-household-income

Pew Research Center. (2018, February 5). Mobile Fact Sheet. Retrieved from http://www.pewinternet.org/fact-sheet/mobile/

Rasid, N. N. B. M., \& Nonis, K. P. (2015). Exploring communication technology behaviour of adolescents with cerebral palsy in Singapore. International Journal of Special Education, 30(3), 17-38.

Robertson, J., Emerson, E., Gregory, N., Hatton, C., Kessissoglou, S. Hallam, A., \& Linehan, C. (2001). Social networks of people with mental retardation in residential settings. Mental Retardation, 39, 201-214. https://doi.org/10.1352/0047-6765(2001)039<0201:SNOPWM>2.0. $\mathrm{CO} ; 2$

Seale, J. (2013). When digital capital is not enough: Reconsidering the digital lives of disabled university students. Learning, Media and Technology, 38(3), 256-269. https://doi.org/10.1080/17439884. 2012.670644

Shoham, S., \& Heber, M. (2012). Characteristics of a virtual community for individuals who are d/Deaf and hard of hearing. American Annals of the Deaf, 157(3), 251-263. Gallaudet University Press. https://doi.org/ 10.1353/aad.2012.1625

Shpigelman, C. N., \& Gill, C. J. (2014a). Facebook use by persons with disabilities*. Journal of Computer-Mediated Communication, 19, 610-624. https://doi.org/10.1111/jcc4.12059 
Shpigelman, C. -N., \& Gill, C. J. (2014b). How do adults with intellectual disabilities use Facebook? Disability and Society, 29(10), 1601-1616. https://doi.org/10.1080/09687599.2014.966186

Siemens, G. (2005). Connectivism: A learning theory for the digital age. International Journal of Instructional Technology and Distance Learning, 2(1). Retrieved from http://www.itdl.org/journal/jan_05/article01.htm

Smart, J. (2016). Disability, society, and the individual (3rd ed.). Austin, TX: Pro-Ed.

Smith, C. (2012, October). Digital marketing ramblings. How many people use the top social media? [Web blog post]. Retrieved from http:// expandedramblings.com/index.php/resource-how-many-people-usethe-top-social-media

Stack-Cutler, H., Parrila, R. K., Jokisaari, M., \& Nurmi, J. (2015). How university students with reading difficulties are supported in achieving their goals. Journal of Learning Disabilities, 48(3), 323-334. https://doi. org/10.1177/0022219413505773

Stough, L. M., Ducy, E. M., \& Holt, J. M. (2017). Changes in the social relationships of individuals with disabilities displaced by disaster. International Journal of Disaster Risk Reduction, 24, 474-481. https:// doi.org/10.1016/j.ijdrr.2017.06.020

Stough, L. M., Sharp, A. N., Resch, J. A., Decker, C., \& Wilker, N. (2015). Barriers to the long term recovery of individuals with disabilities following disaster. Disasters, 40(3), 387-410. https://doi.org/10.1111/ disa.12161

Valcourt-Pearce, C. C. (2015). Technology and multiple disabilities: Learning what works for cree. Odyssey: New Directions in Deaf Education, 16, 51-55.
Wenger, E., McDermott, R., \& Snyder, W. M. (2002). Cultivating communities of practice. A guide to managing knowledge. Cambridge, MA: Harvard Business School Press.

Wenger-Trayner, E. \& Wenger-Trayner, B. (2015). Communities of practice -A brief introduction. Retrieved from https://wenger-trayner.com/ wp-content/uploads/2015/04/07-Brief-introduction-to-communitiesof-practice.pdf

Wilson, S., Washington, L., Engel, J., Ciol, M., \& Jensen, M. (2006). Perceived social support, psychological adjustment, and functional ability in youths with physical disabilities. Rehabilitation Psychology, 51(4), 322-330.

World Wide Web Consortium. (2005). Introduction to web accessibility. In S. Henry (Ed.), Web accessibility initiative. Retrieved from https:// www.w3.org/WAl/intro/accessibility.php\#more-info

World Wide Web Consortium. (2012). Web content accessibility guidelines. In S. Henry (Ed.), Web accessibility initiative. Retrieved from https:// www.w3.org/WAl/intro/wcag.php

Wright, A. C., \& Taylor, S. (2014). Advocacy by parents of young children with special needs: Activities, processes, and perceived effectiveness. Journal of Social Service Research, 40(5), 591-605. https://doi.org/ 10.1080/01488376.2014.896850

How to cite this article: Sweet KS, LeBlanc JK, Stough LM, Sweany N. Community building and knowledge sharing by individuals with disabilities using social media. J Comput Assist Learn. 2019;1-11. https://doi.org/10.1111/jcal.12377 